\title{
Thermodynamic constraints on the origin of abundant plagioclase by gabbroic mush entrainment, Steens Basalt, SE Oregon
}

Strasser VE1, BoHrSON WA2, TOTH C1 , GRUNDER $\mathrm{AL}_{3}$

1Central Washington University [valerie.strasser@cwu.edu] 2 Colorado School of Mines [bohrson@mines.edu] 3Oregon State Unviersity [grundera@geo.oregonstate.edu]

The Steens Basalt, the most mafic member of the Columbia River Basalt Group, contains large (up to $6 \mathrm{~cm}$ ) and abundant (up to $40 \%$ ) plagioclase. The goal of this study is to use thermodynamic modelling to document the origin of these plagioclase. Steens Mountain (SE Oregon) is subdivided into a more evolved upper Steens and more mafic lower Steens. Giant Plagioclase Basalts (GPB), which have large and abundant plagioclase, are more common in lower Steens than upper Steens. Previous work suggests that lower Steens was dominated by magma recharge whereas upper Steens experienced more crustal assimilation [1 and references therein]. Typically, lower Steens plagioclase are in $\mathrm{Sr}$ isotopic equilibrium with associated groundmass (GM) and have lower concentrations of incompatible trace elements (e.g., La. $\mathrm{Ba}$ ) whereas upper Steens plagioclase exhibit more crystalGM isotope disequilibrium and have higher $\mathrm{Ba}$ and La. Based on these data, the origin of Steens plagioclase is hypothesized to involve entrainment of a plagioclase-bearing cumulate [2]. Using the Magma Chamber Simulator (MCS), a mass/energyconstrained thermodynamic model [3], input parameters like initial composition and temperature were varied. MCS results incorporating entrainment of a plagioclase-bearing cumulate coupled with recharge and fractional crystallization reproduce whole rock and in situ data. Specifically, entrainment into more mafic lower Steens magmas yields substantial plagioclase resorption. Upon cooling, significant plagioclase crystallizes, consistent with crystal-GM isotopic equilibrium and lower $\mathrm{Ba}$ and La. Entrainment into more evolved upper Steens yields some plagioclase resorption, followed by new growth, consistent with a more heterogeneous in situ record. Preliminary MCS results also highlight the likely contribution of crustal assimilation in upper Steens; additional modelling will further test this. This study, the first that employs mass and energy-balanced thermodynamic constraints on the crystallization of abundant plagioclase, will illuminate potential origins of GPB, which are found in flood basalts and other settings worldwide.

[1] Moore et al. (2018) Geosphere. 14, 2505-2532. [2] Toth (2018) MS thesis, Central Washington University. [3]

Bohrson et al. (2014) Journal of Petrology. 55, 1685-1171. 